\title{
Elección de contrato y estrategias de vida: estudio de caso de la cadena de la leche en Matiguás, Nicaragua
}

Juan Carlos Polvorosa Narváez

Departamento de Economía Aplicada, Universidad Centroamericana - UCA. Rotonda Rubén Darío, 500mts al oeste, Managua, Nicaragua. E-mail: jpolvorosa@ns.uca.edu.ni

Recibido: octubre de 2007 / Aceptado: octubre de 2007

A PESAR DE LA EXISTENCIA DE MERCADOS DINÁMICOS DE LECHE EN EL municipio de Matiguás -con el potencial de reducir la pobreza en esta zona rural- los hogares enfrentan dificultades para articularse a la cadena de la leche y se ven limitados de disfrutar los posibles beneficios que podrían obtener al participar. La falta de infraestructura y de servicios de apoyo al intercambio limita el desempeño de la cadena, y a su vez, bloquea el acceso de los hogares a la misma, creando procesos de exclusión o permitiendo el acceso a la cadena bajo condiciones desfavorables. Algunos hogares, enfrentando procesos de exclusión económica y social, participan en transacciones entrelazadas patrón-clientelistas como única manera de acceder a la cadena de la leche. Esta situación provoca la segmentación de la cadena de la leche: los diferentes hogares operan en diferentes canales para conectarse a la cadena, cada uno con su propia lógica productiva y comercial, y desempeño distributivo y participativo. En este contexto, presentamos un diagnóstico exploratorio acerca de las oportunidades y limitantes de los medios de vida de los hogares rurales de Matiguás en presencia de una fuerte dinámica en la cadena de la leche.

Palabras Claves: leche-comercio / cadena / valor (economía) / Matiguás-Nicaragua

\section{Introducción}

En Nicaragua, las actividades agropecuarias son muy importantes. Juntas, tanto la agricultura como la ganadería, generan el 28.1\% del producto interno bruto de la nación y el 42.6\% del empleo nacional (INEC, 2001). La ganadería en especial ha demostrado ser un sector con un alto potencial de crecimiento económico. En 2004, el 23.53\% de las exportaciones nacionales provinieron de actividades económicas relacionadas con la ganadería: exportaciones de ganado en pie, carne, queso y otros productos derivados de la leche (BCN, 2004). El crecimiento del sector ganadero -gracias a la dinámica de mercados nacionales e internacionales- ha estimulado la producción de leche en Nicaragua y su importancia se ve evidenciada en el Plan Nacional de Desarrollo, que identifica, en la 
zona central de Nicaragua, a los municipios de Matiguás, Muy Muy, Río Blanco y Paiwas como poseedores del más alto potencial para la producción de leche. El crecimiento de este mercado tiene el potencial de reducir la pobreza rural entre los agentes económicos dedicados a la producción de leche. Sin embargo, en Matiguás los hogares rurales enfrentan dificultades para articularse a este dinámico sector y sufren restricciones para disfrutar de los posibles beneficios de la producción y venta de leche.

Por ende, incluso ante la presencia de mercados dinámicos de leche, hay hogares que no pueden o no son capaces de aprovechar los beneficios potenciales asociados a su producción. Esta situación se expresa concretamente en la segmentación del mercado de la leche, en el que diferentes hogares operan en diferentes canales para conectarse. Los productores en Matiguás cuentan con diferentes opciones al momento de vender su leche: centros de acopio, intermediarios comerciales y queseros semi-industriales y artesanales. Cada uno de estos segmentos opera con su propia lógica y está asociado con niveles altos o bajos de ganancias, mercados más o menos dinámicos, y mayores o menores niveles de valor agregado. A pesar de que los centros de acopio, y tal vez los queseros semi-industriales, sean los segmentos con los niveles más altos de valor agregado -donde se pueden obtener los niveles más altos de ganancias- muchos hogares eligen o se ven obligados a vender su leche a las otras dos opciones. Dependiendo de a quién vendan su leche, los hogares pueden ser clasificados entre aquellos bien conectados y aquellos pobremente conectados al mercado. En el primer grupo se encuentran aquellos hogares que se articulan a los segmentos más dinámicos y beneficiosos; mientras que en el segundo se encuentran aquellos hogares que toman parte en los segmentos menos dinámicos y menos beneficiosos.

El objetivo de este artículo es presentar una descripción y análisis general de las dinámicas de crecimiento e inclusión/exclusión de los hogares en los mercados de leche en el municipio de Matiguás y las posibilidades de intensificación en la producción de leche. Con esta meta en mente desarrollamos un marco teórico-conceptual que consideramos apropiado para inspirar nuestro diagnóstico investigativo. Tomamos como punto de partida el marco de Medios de Vida Sostenibles, que nos permitirá analizar y comprender las estrategias de vida de los hogares rurales en su contexto local, y en particular, su articulación con elementos del ambiente institucional local que facilitan u obstaculizan el acceso a los diferentes mercados de la leche. Solamente de esta manera podemos aspirar a tener un entendimiento más completo y apropiado de la naturaleza y condiciones de las estrategias de vida de los actores económicos rurales.

Dado que dentro del marco de Medios de Vida Sostenibles, nuestra elaboración conceptual del ambiente institucional local resulta todavía algo superficial, consideramos necesario complementar y elaborar aún más esta parte del marco, en particular las interacciones de las estrategias de vida de los hogares con los sistemas de intercambio del "mundo real" en los que pueden o no participar bajo determinadas condiciones. Encontramos inspiración en la literatura sobre mercados y costos de transacción, así como en la más reciente iniciativa de "hacer que los mercados funcionen para los pobres" (making markets work for the poor). Estas elaboraciones nos acercarán más a desarrollar dos aspectos clave de particular interés para nuestra investigación. El primero concierne a la racionalidad de los hogares y la "elección de contrato" (contract choice) en el contexto de mercados rurales 
"reales" que son imperfectos, inestables y, en muchas ocasiones, hasta inexistentes. El segundo es el concepto de "cadena de valor" que representa un enfoque más operativo para describir y analizar los mercados "reales" de bienes. Haciendo uso de la literatura existente sobre cadenas de valor, pero complementándola con perspectivas de la nueva economía institucional y teoría del capital social, desarrollamos un enfoque de cadena de valor en donde la misma es entendida como una cadena de actores y transacciones que está social, institucional y geográficamente situada. Siguiendo la pista general de Williamson (1994), la cadena de valor debe ser entendida como un "arreglo institucional" particular, socialmente construido y funcionando en interacción con el más amplio "ambiente institucional" rural (en nuestro caso, el Municipio de Matiguás). El desempeño productivo y comercial, así como distributivo y participativo, en gran medida depende de las reglas del arreglo institucional que determina la manera en que los hogares pueden conectarse y participar en la cadena, hasta qué punto y bajo qué condiciones tienen acceso a la cadena, y qué parte de valor agregado pueden retener. Con estos bloques conceptuales añadidos creemos haber completado un marco lo suficientemente relevante y completo que nos permite el análisis del tema en cuestión: las oportunidades y limitantes de estrategias de vida de los hogares pobres rurales en el contexto de un creciente mercado de la leche en Matiguás.

La primera sección del artículo presenta de manera amplia el marco de Medios de Vida Sostenibles e introduce el concepto de ‘sistemas de intercambio' como una explicación alternativa a las 'estructuras y procesos de transformación' que median y determinan el acceso de los hogares a recursos y oportunidades. En la segunda sección se hace énfasis en los procesos de exclusión de los hogares de los sistemas de intercambio que son clave para sus estrategias de vida. En la sección tres se expone que la exclusión induce a los hogares a establecer arreglos contractuales pobres con otros actores para asegurar sus medios de vida. Estos arreglos contractuales son caracterizados como relaciones entrelazadas patrónclientelistas de tipo extractivas, que tienen consecuencias para las estrategias de vida de los hogares. La sección cuatro ilustra el concepto de sistemas de intercambio (rurales) en el contexto de cadenas de valor de productos agropecuarios y centra la atención en las consecuencias de los arreglos contractuales pobres establecidos entre actores en términos del desempeño y gobierno de la cadena. La sección cinco aplica el marco a la cadena de la leche en Matiguás. La sección seis concluye con sugerencias para futuras investigaciones.

\section{Marco de Medios de Vida Sostenibles}

El punto de partida para la elaboración de nuestro marco teórico es el marco de Medios de Vida Sostenibles (MVS), el cual permite el estudio y análisis del contexto en el que las personas de las zonas rurales viven -acceden a activos y tienen capacidad para darles un uso apropiado-, de las instituciones y organizaciones que moldean sus medios de vida, y de las diferentes estrategias que adoptan para alcanzar sus metas (DFID,1999). En palabras de Ellis (2000:8), "un medio de vida comprende los activos, las actividades y acceso a éstos (...) que juntos determinan la subsistencia obtenida por el individuo u hogar". El MVS va más allá de los aspectos técnicos y productivos de las actividades de subsistencia, y llama sustancialmente la atención a la dimensión económica y social de la vida rural. 


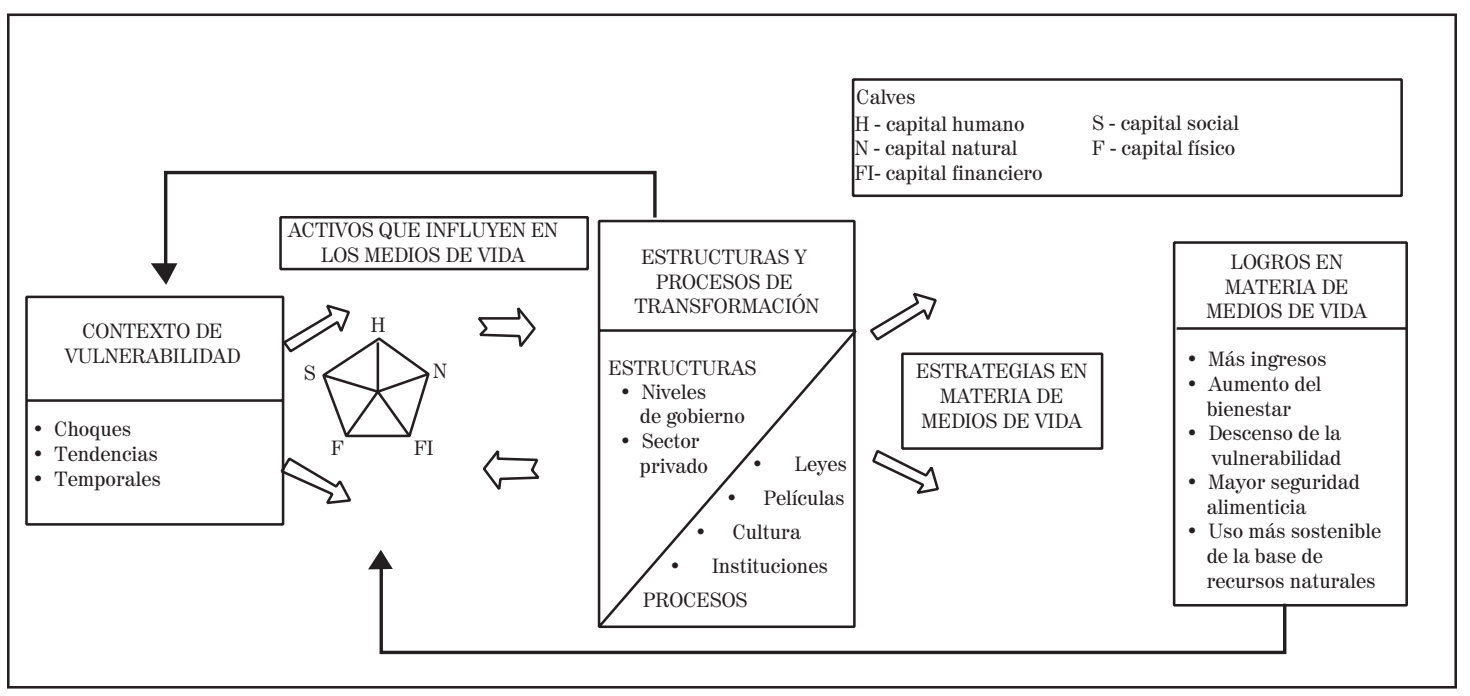

$50 \quad$ Ilustración 1: Marco de Medios de Vida Sostenibles Fuente: DFID (1999)

Según el DFID (1999), los medios de vida pueden ser descritos por sus cinco principales elementos: contexto de vulnerabilidad, activos de medios de vida, estructuras y procesos de transformación, estrategias de vida, y logros de las estrategias de vida. El marco pone énfasis en el acceso de los hogares a los activos como primer determinante de las estrategias de vida disponibles para los hogares. Una idea central, sin embargo, es que el acceso a los activos así como a las oportunidades para valorizar los mismos dentro de estrategias de vida, es moldeado por las estructuras y procesos de transformación que median las opciones en términos de estrategias de vida viables (con similar acceso a activos) y consecuentemente co-determinan su resultado o logro. Este es el punto central del análisis y será desarrollado más ampliamente a continuación.

El contexto de vulnerabilidad se define como el ambiente externo en el que viven las personas y que se encuentra fuera de su control. El contexto de vulnerabilidad tiene un impacto directo en los activos de los hogares, y por consiguiente, en sus estrategias de vida y posibles resultados, dado que puede mantener, aumentar o destruir los activos de las personas a través de choques, tendencias y estacionalidad. El pentágono en la Ilustración 1 representa los cinco tipos de activos que los hogares pueden tener: capital humano, capital natural, capital financiero, capital físico y capital social.

Dentro del marco MVS, estructuras y procesos de transformación son los elementos que influyen y determinan el acceso a activos, estrategias de vida y su consiguiente retorno. El marco del DFID se queda corto de explicar en detalle cómo estos elementos se combinan en procesos que determinan el acceso a activos y oportunidades para valorizar los mismos. Más aún, la terminología empleada por el DFID - estructuras y procesos de transformaciónes algo confusa pues junta muchos elementos bajo estos términos, en especial cuando se refiere a 'estructuras' y 'organizaciones'. Estos conceptos no son explicados con suficiente 
claridad en el marco y no se operacionaliza en detalle cómo los mismos interactúan con las estrategias de vida de los hogares rurales.

Para mayor claridad, en este artículo se propone el uso del concepto de 'sistemas de intercambio', que se refiere a mecanismos que median el acceso de los hogares rurales a los activos y a las oportunidades para valorizar los resultados que pueden generar con su uso. ${ }^{1}$ El concepto 'sistemas de intercambio' es parte de una manera más concreta de especificar estructuras y procesos de transformación y cómo éstos interactúan con las estrategias de vida de los hogares, mediando su acceso a activos y a oportunidades para valorizar los mismos.

\subsection{Sistemas de intercambio}

Inspirados por Johnson et al. (2005), creemos que un enfoque analítico apropiado para el análisis de 'sistemas de intercambio' debe dedicar atención a los siguientes componentes complementarios: a) la cadena de arreglos contractuales, específicamente la estructura de gobierno concerniente a las transacciones de intercambio entre vendedores y compradores (usualmente incluye también varios intermediarios entre los vendedores iniciales y los compradores/consumidores finales), b) la infraestructura necesaria para físicamente permitir el intercambio, c) el conjunto de servicios de apoyo al proceso de intercambio y d) el ambiente institucional global en el cual las transacciones y arreglos contractuales del sistema de intercambio (como una estructura de gobierno particular) tienen lugar.

Por motivos pragmáticos -y sin tratar de restar importancia al acceso a activos- de ahora en adelante nos enfocaremos y analizaremos los 'sistemas de intercambio' en términos de mecanismos por medio de los cuales los actores económicos intercambian productos. En este sentido, un 'sistema de intercambio' es un mecanismo que permite a las personas intercambiar, en otras palabras, comprar y vender. 


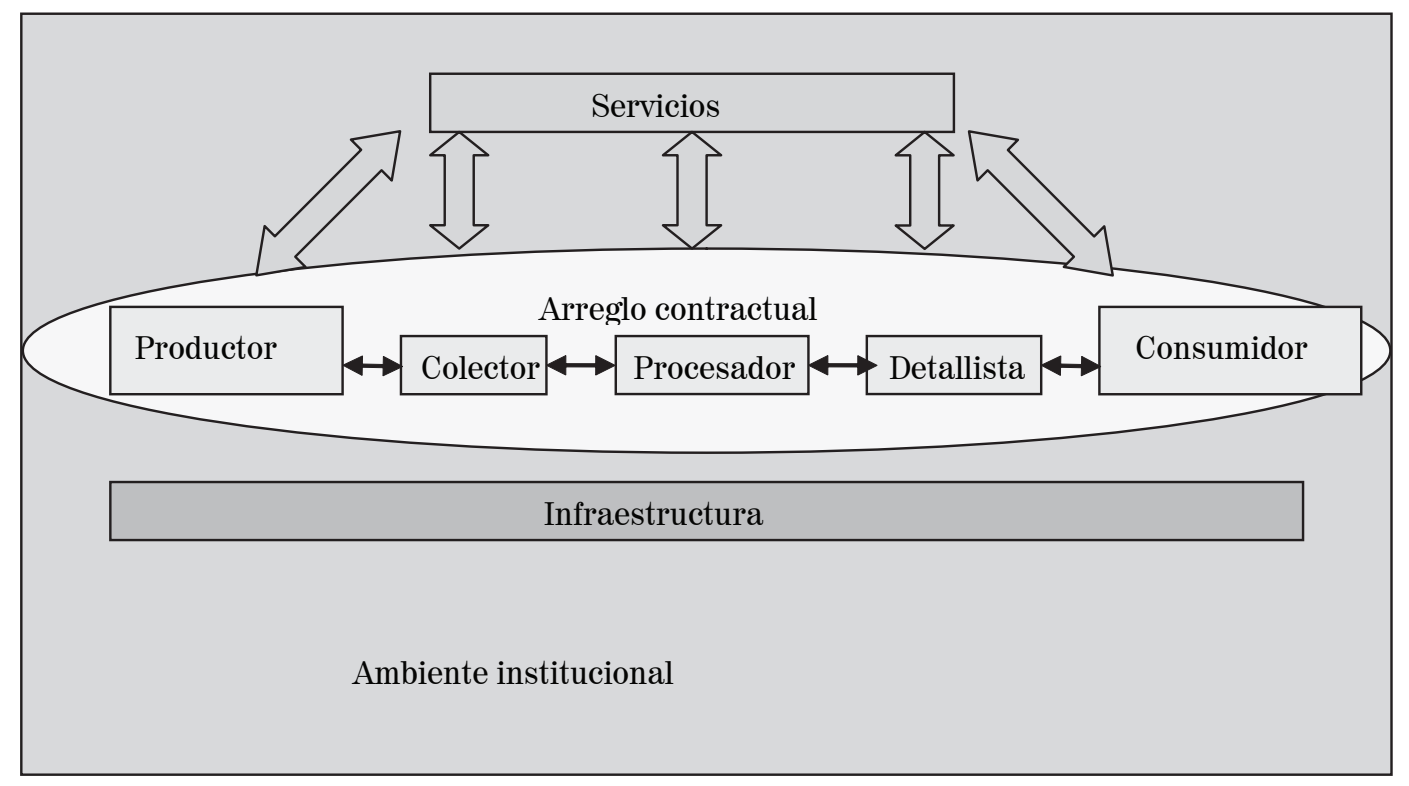

Ilustración 2. Sistema de intercambio

Fuente: Elaboración propia, basada en Johnson et al. (2005)

En un 'sistema de intercambio', los actores básicos son los compradores, vendedores y posiblemente intermediarios (transportistas, procesadores, detallistas) que participan en las transacciones de intercambio, como se puede apreciar en la Ilustración 2. Estos actores enmarcan sus intercambios en arreglos institucionales o contractuales, también llamados 'estructuras de gobierno'. ${ }^{2}$ Estructura de gobierno se refiere a las reglas particulares -voluntariamente diseñadas- que gobiernan los arreglos contractuales ensamblados y seguidos por los actores económicos (individuos/organizaciones) para guiar sus interacciones (intercambios) (Williamson, 1994:79). En la práctica, un sistema de intercambio puede tomar diferentes formas, bajo las cuales las transacciones económicas entre los actores económicos tienen lugar. En este sentido, la forma particular que la estructura de gobierno toma está al centro de un sistema de intercambio y representa la característica que lo define. Los actores pueden utilizar una variedad de estructuras de gobierno (formales e informales) para sus transacciones (Williamson, 1991:269), así el intercambio puede tener lugar bajo transacciones en el mercado o puede ser desarrollado bajo arreglos de intercambio híbridos (cadenas de valor) y/o arreglos formales fuera del mercado (integración vertical), todos los cuales representan arreglos contractuales entre actores económicos.

Los sistemas de intercambio no existen en abstracto ni funcionan automáticamente. Apoyando a los actores económicos en sus procesos de intercambio está la infraestructura básica que permite que la transacción de intercambio tenga lugar. La infraestructura incluye todos los requerimientos físicos necesarios para apoyar la realización de la transacción: carreteras, caminos (en buen estado), electricidad, agua, telecomunicaciones e información. Adicionalmente a la infraestructura, los sistemas de intercambio necesitan la provisión de servicios que apoyen el intercambio, éstos incluyen: crédito para capital de trabajo comercial, 
seguros, asistencia técnica para procesamiento, empaque y conservación, bodegas, servicios legales para la elaboración de contratos y su cumplimiento, comunicación y servicios de información acerca de precios y calidad, entre otros. La falta de organizaciones que provean estos servicios y/o la falta de infraestructura básica en áreas rurales dan lugar a problemas de acceso o condicionan la manera en que los hogares acceden a las oportunidades de intercambio. La falta de estos elementos limita el acceso de algunos hogares a los sistemas de intercambio, así como su desempeño. En casos extremos, la ausencia de infraestructura (caminos en particular) puede crear condiciones de falla total del mercado para algunos hogares. En otros casos -inclusive con infraestructura- algunos hogares pueden participar en sistemas de intercambio sólo bajo condiciones desfavorables, producto de mercados poco desarrollados.

Junto a la infraestructura y los servicios de apoyo a los intercambios entre actores económicos, está el ambiente institucional en el cual el sistema de intercambio como un todo se encuentra inmerso. El ambiente institucional se refiere al marco general que sirve como cimiento a los contratos específicos o arreglos institucionales entre los individuos. Se encuentra compuesto por las reglas (políticas, sociales y culturales) del juego que establecen las bases para la interacción humana (North, 1990:3). Como se muestra en el Cuadro 1, Bastiaensen et al. (2002:10-1) incluyen en su definición de ambiente institucional las 'estructuras sociales' y la 'cultura'. Desde esta perspectiva, el ambiente institucional provee una amplia herencia social, histórica y cultural a partir de la que se ensamblan formas concretas de estructuras de gobierno (Williamson, 1994:79-80). El ambiente institucional interactúa con y da forma a las estructuras de gobierno diseñadas y utilizadas por los actores económicos. Éste ejerce influencia en las mismas y en su desempeño a medida que sus elementos infiltran los procesos conscientes de diseño e implementación de estructuras de gobierno interpretadas por los actores económicos para guiar sus interacciones.

Cuadro 1: Componentes del ambiente institucional.

\begin{tabular}{|l|l|}
\hline \multicolumn{2}{|c|}{ Ambiente institucional } \\
\hline $\begin{array}{l}\text { Estructuras } \\
\text { sociales }\end{array}$ & $\begin{array}{l}\text { Relaciones sociales } \\
\text { Redes } \\
\text { Organizaciones }\end{array}$ \\
\hline Reglas & $\begin{array}{l}\text { Reglas formales } \\
\text { Reglas informales }\end{array}$ \\
\hline Cultura & $\begin{array}{l}\text { Percepciones } \\
\text { Identidades }\end{array}$ \\
\hline
\end{tabular}

Fuente: Bastiaensen et al. (2002)

La forma que toma la estructura de gobierno es moldeada por e interactúa con el ambiente institucional en el cual está inmerso. Relacionados muy de cerca con el intercambio están los costos de transacción, que pueden afectar la viabilidad de los intercambios potencialmente interesantes. Costos de transacción asociados con información asimétrica e imperfecta, así como con comportamientos oportunistas, pueden incrementar los costos de transacción 
explícitos de transporte, comunicación y administración del intercambio. Esta situación se torna peor en países en desarrollo, especialmente en áreas rurales caracterizadas por falta de infraestructura, presencia de riesgos asociados al oportunismo, incertidumbre, flujos de información débiles, problemas de coordinación y débil ambiente institucional. En conjunto, éstos pueden incrementar los costos de transacción limitando el acceso de los hogares a los mercados e impidiendo la expansión de los mismos (Richards, 2005:10).

Para Williamson (2003) un mercado es simplemente una alternativa contractual frente a otras maneras de asignar recursos en la economía. La posibilidad de realizar el intercambio en el mercado o no y si éste constituye el mejor arreglo institucional para organizar el intercambio, está estrechamente relacionada al tema de los costos de transacción. Para este autor, riesgos contractuales que surgen de la naturaleza de la transacción, pueden aumentar los costos del intercambio y crear la necesidad de usar sistemas de intercambio alternativos que reduzcan los costos de transacción y permitan el intercambio. Con el propósito de reducir los costos de transacción, ésta puede llevarse a cabo bajo modos de intercambio o estructuras de gobierno alternativas. En este sentido, las transacciones que difieren en sus atributos son ubicadas en estructuras de gobierno que difieren en sus costos y competencia (Williamson, 1994:88). De acuerdo con Williamson (1991:285), las transacciones se llevan a cabo en estructuras de gobierno cuyo propósito es permitir que el intercambio tenga lugar al nivel de costo de transacción más bajo posible. ${ }^{3}$ Cuando los costos de transacción son extremadamente altos, el sistema de intercambio del mercado no funcionará bien (o del todo) producto de fallas asociadas a los costos de transacción. Este tendrá lugar solamente si los beneficios netos del intercambio son mayores que los costos de la transacción.

\section{Acceso a sistemas de intercambio}

Habiendo definido los sistemas de intercambio, enfocaremos ahora nuestra atención en el funcionamiento y desempeño de los sistemas de intercambio en términos de acceso de los hogares rurales. La capacidad para usar un activo en una manera óptima y beneficiosa depende -por lo menos parcialmente- de la existencia y funcionamiento de los sistemas de intercambio. Comprender la naturaleza de los sistemas de intercambio y el funcionamiento de los mismos es crucial para ayudarnos a entender cómo las oportunidades de vida son moldeadas y restringidas. Los sistemas de intercambio son importantes particularmente en términos de posibilidades de estrategias de vida de los hogares (pobres) porque éstos constituyen el principal mecanismo de transmisión entre el crecimiento económico más amplio y las oportunidades de los hogares (Johnson et al. 2005:2). Su desempeño determina hasta qué punto los hogares participan o no en los sistemas de intercambio y se benefician de los mismos.

En áreas rurales en donde la infraestructura está ausente y hay una nula o pobre provisión de servicios financieros y no-financieros básicos, y/o en donde el ambiente institucional no ayuda al cumplimiento de las obligaciones contractuales, ningún sistema de intercambio podrá desarrollarse. En casos menos extremos, los sistemas de intercambio pueden funcionar pero algunos individuos o grupos, especialmente los grupos socio-económicos más vulnerables, pueden ser excluidos de éstos (Johnson, 2004:2). Los sistemas de intercambio pueden fallarles a los pobres cuando éstos no son capaces de tener acceso a los mismos, 
o solamente pueden lograr acceso bajo arreglos contractuales pobres. En este contexto, Dorward y Poole (2003, citado en Dorward y Kydd, 2005:10) identifican tres tipos de fallas de acceso que excluyen a los hogares de los sistemas de intercambio: 1) falta de recursos, 2) fallas en las transacciones y 3) exclusión social.

A veces los hogares se ven imposibilitados de conseguir acceso a sistemas de producción e intercambio como resultado de la falta de recursos para participar en ciertas actividades productivas y sus asociados sistemas de intercambio. En este sentido, se debe de diferenciar entre los activos mínimos que los hogares deben de tener para asegurar su subsistencia (tierra, en el caso de actividades agrícolas y pecuarias) y los activos adicionales necesarios (servicios financieros y/o asistencia técnica) y provistos por organizaciones.

Las fallas en las transacciones provocan que los hogares rurales sean excluidos de los sistemas de intercambio en la medida en que los costos de transacción pesan demasiado para las pequeñas transacciones. Adicionalmente, los hogares pueden ser excluidos cuando sufren de marginación social o geográfica. Para nosotros, las fallas en las transacciones se explican por los altos costos de transacción asociados a situaciones de información asimétrica, falta de infraestructura, costos de transporte y de economías de escala en el transporte y comercialización de los productos.

Además, para Dorward y Poole (2003, citado en Dorward y Kydd, 2005:10), los hogares rurales pueden sufrir fallas de acceso a los sistemas de intercambio como resultado de la exclusión social o discriminación basada en características personales de los individuos (casta, clase, tribu, género, religión o afiliación política). La exclusión social es también una consecuencia de la falta de capital social. ${ }^{4}$ En el contexto del marco de estrategias de vida, el capital social constituye un activo -disponible para los hogares rurales - que puede ayudar a asegurar el acceso a activos y estrategias de vida.

Bajo estecontexto, podemos definir alos pobres como “aquellos humanos que, por alguna razón u otra, casi sistemáticamente terminan en el lado perdedor de las múltiples negociaciones que ocurren alrededor de los recursos y oportunidades disponibles" (Bastiaensen $e t$ al., 2005:981). Como discutiremos en la siguiente sección, esto tiene una expresión concreta en términos de acceso de los hogares rurales a los sistemas de intercambio, los que pueden restringir sus estrategias de vida y posibilidades de avance.

\section{Estrategias de vida y opciones de contratos}

Como mencionamos antes, los sistemas de intercambio son importantes para los hogares rurales y sus medios de vida en la medida en que su funcionamiento determina el acceso de éstos a las oportunidades de intercambio. Los hogares pueden sufrir de exclusión económica y/o social a los sistemas de intercambio. Sin embargo, comúnmente los hogares encuentran maneras de obtener acceso; en muchas ocasiones lo hacen por medio de arreglos institucionales desfavorables. Aún siendo víctimas de procesos de exclusión, los hogares logran participar en sistemas de intercambio que son importantes para sus estrategias de vida, aunque lo hagan bajo condiciones desfavorables. 
Dorward y Kydd (2005:11) identifican dos tipos de arreglos institucionales (desfavorables) que implican exclusión social: 1) mercados segmentados socialmente discriminatorios y 2) entrelazamientos extractivos (extractive interlocking). En los mercados segmentados socialmente discriminatorios el acceso o las condiciones de precios discriminan entre los diferentes participantes del mercado en base a características étnicas, de género, de edad, o cualquier otra característica social. Estos mercados pueden excluir completamente a algunas categorías o grupos sociales de participar en los mercados, pueden limitar el acceso a ciertos segmentos más beneficiosos o pueden aplicar diferentes términos de intercambio a diferentes grupos sociales. Los entrelazamientos extractivos son formas particulares de contratos bajo los cuales un individuo toma parte casi de manera simultánea en varias transacciones y se ve limitado de participar en transacciones alternativas y -posiblementemás beneficiosas con otros individuos. Bajo este esquema, todas las transacciones se encuentran condicionadas a la realización del resto de las transacciones; es así que un hogar toma prestado de, trabaja para, alquila tierra de, y vende a una sola persona: propietario/ prestamista/ intermediario comercial. Este tipo de arreglos institucionales es común entre los hogares rurales como medio para garantizar el acceso a activos y oportunidades de estrategias de vida cuando enfrentan procesos de exclusión económica y/o social y para asegurar algún tipo de protección ante riesgos bajo condiciones de incertidumbre.

A pesar de la naturaleza desfavorable de algunos arreglos contractuales, los hogares rurales los eligen como único medio para obtener acceso a recursos y oportunidades necesarias para sus estrategias de vida. Aquellos con capacidad limitada para asegurar un préstamo de una institución financiera comúnmente toman parte en contratos entrelazados de crédito y productos con intermediarios comerciales como una manera de obtener acceso a créditos. Normalmente, los créditos son otorgados a los hogares en efectivo o especies. La tasa de interés suele ser muy baja y en algunas ocasiones hasta cero y el pago del crédito se hace, típicamente, a través de la transferencia de la producción del hogar a un precio menor al establecido en el mercado. La naturaleza explotadora del contrato tiene su explicación en la capacidad que los intermediarios tienen para empujar el ingreso de los hogares a su nivel de reserva y así extraer el máximo excedente de los hogares (Bardhan y Urdí, 1999:116). Gangopadhyay y Sengupta (1987:341) lograron probar que esto es una consecuencia de imperfecciones en los mercados de crédito más que de la incapacidad -en comparación con los intermediarios comerciales- de los hogares rurales de lograr acceso a los mercados de productos. Los autores argumentan que este resultado se refuerza aún más si los hogares enfrentan dificultades de acceso a los mercados de productos. En consecuencia, a pesar de su naturaleza explotadora, las relaciones entrelazadas extractivas pueden ser elegidas voluntariamente por hogares que enfrentan procesos económicos y sociales de exclusión, como los únicos arreglos contractuales que les permiten acceso a activos y oportunidades.

En las zonas rurales, los contratos entrelazados extractivos usualmente se encuentran inmersos en relaciones patrón-cliente que para los hogares representan sustitutos de seguros ante emergencias. La naturaleza de las actividades agrícolas y pecuarias caracterizadas por incertidumbre, emergencias y ausencia de mercados formales de seguros, hacen de los seguros contra riesgos un aspecto importante a considerar al momento de elegir entre diversos arreglos contractuales (Hayami y Otsuka, 1993:22). La presencia de riesgos -ante la falta de acceso a créditos con fines de seguro ${ }^{5}$ - empujan a los hogares rurales a implementar 
diversas estrategias para hacerles frente (Binswanger y Rosenzweig, 1986:508; Barret $e t$ $a l ., 2001: 322)$. Estas estrategias incluyen la opción de arreglos contractuales caracterizados por relaciones patrón-cliente como medios para conseguir un sustituto de seguro en un ambiente caracterizado por incertidumbre.

Las relaciones patrón-cliente son relaciones personalizadas de largo plazo entre individuos por medio de redes verticales basadas en elementos de desigualdad de poder. En estas relaciones una persona de status socio-económico superior (el patrón) provee a individuos pobres de menor status (el cliente) alguna forma de protección económica y social (créditos de emergencia) y beneficios (acceso a recursos y servicios de mercado) a cambio de su apoyo, algunos servicios de trabajo y lealtad (Scout, 1972:9). La figura del patrón puede tomar muchas formas: prestamista, intermediario comercial y/o terrateniente, de quien el cliente obtiene protección contra emergencias y acceso a sistemas de intercambio a cambio de "aceptar el control por parte del patrón de su acceso (del cliente) a los mercados (...) así como de su habilidad para transformar plenamente alguno de sus recursos" (Eisenstadt y Roniger, 1980:71), reforzando el carácter explotativo de los contratos entrelazados.

Combinando ambos tipos de contratos y relaciones, resulta común encontrar hogares rurales tomando parte en relaciones entrelazadas extractivas y patrón-clientelistas a la misma vez y con el mismo actor. ${ }^{6}$ Estos tipos de arreglos contractuales tienen efectos negativos para las estrategias de vida de los hogares porque los sumergen, encierran y vuelven dependientes de otros actores para obtener acceso a recursos y sistemas de intercambio. La consecuencia general es que los "hogares son excluidos de tomar parte en transacciones alternativas y más remunerativas con otros actores” (Dorward y Kydd, 2005:11). No se trata de que no existan otros tipos de arreglos institucionales que podrían resolver estos mismos problemas, por ejemplo, a través de la organización de los hogares rurales en cooperativas. El problema radica en que el cambio a un contrato o arreglo institucional alternativo conlleva un costo. Dado el compromiso/dependencia personal de los hogares a su patrón, los hogares consideran la perspectivas de largo plazo de futuros beneficios y posibles pérdidas al establecer contratos alternativos. Esto sirve para disuadirlos de tomar parte en transacciones alternativas con otros individuos (Hayami y Otsuka, 1993:83).

En su búsqueda por obtener algún tipo de seguridad y protección, los hogares se colocan en relaciones y estructuras sociales que bloquean sus perspectivas futuras de mejorar sus medios de vida (Word, 2003:455). A la vez, estas dinámicas de elección de contratos para obtener acceso a sistemas de intercambio - percibidas como viables-también retroalimentan de manera negativa el desempeño y funcionamiento de los sistemas de intercambio en la medida en que los incentivos son truncados por estos contratos entrelazados y explotativos. Esto será discutido en la siguiente sección e ilustrado con el estudio de caso.

Además de la exclusión económica y social que obliga a los hogares a participar en arreglos contractuales pobres, éstos también pueden auto-excluirse de ciertos tipos de organizaciones y arreglos institucionales. Los hogares evalúan y deciden entre diferentes arreglos institucionales basados en modelos mentales subjetivos (North, 1990:8) sobre la manera en que las cosas se hacen, las relaciones sociales se estructuran y las personas se comportan. El ambiente institucional se encuentra compuesto de relaciones sociales, 
reglas y cultura. El mismo provee una herencia social e histórica amplia en la que se ensamblan formas concretas de estructuras de gobierno (Williamson, 1994:79-80) y en la que interactúan y toman forma las estructuras de gobierno diseñadas y empleadas por los actores económicos. Directamente relacionadas a la cultura están las condiciones histórico-estructurales y experiencias vividas en el pasado que han generado y alimentado las percepciones e identidades que alimentan estos modelos subjetivos imperfectos con los cuales los hogares evalúan y (re)crean su realidad (Bastiaensen et al., 2005:980). En este sentido, los hogares que no sufren ni exclusión social ni exclusión económica, pueden aún así auto-excluirse de arreglos contractuales (potencialmente) beneficiosos que pueden ser vistos por los hogares como desfavorables en base a sus modelos imperfectos y subjetivos de leer la realidad. Por ejemplo, en muchos países del mundo la organización de pequeños productores en cooperativas es difícil debido a las experiencias fallidas impulsadas por políticas públicas para fomentar o apoyar la formación de cooperativas. Éstas han contribuido a crear percepciones negativas entre los productores sobre este tipo de organizaciones (Van Der Meer, 2006:215).

\section{Cadenas de valor y sistemas de intercambio}

En esta sección ampliamos aún más el marco teórico e ilustramos nuestro concepto de sistemas de intercambio en el contexto de cadenas de productos agrícolas. Usualmente, los sistemas de intercambio en zonas rurales toman la forma concreta de cadenas de valor. Las cadenas de valor son particularmente relevantes para los productos agrícolas debido a que la naturaleza perecedera ${ }^{7}$ de los mismos demanda una deliberada e intensa coordinación -ex-ante y ex-post- en los procesos de producción e intercambio. El nivel de coordinación necesario es más fácil de garantizar si se organiza la producción e intercambio en empresas verticalmente integradas o en cadenas de valor híbridas con un gobierno mixto de mercado y jerarquía ${ }^{8}$ (Goletti, 2005:21). Por tal motivo, muchos sistemas de intercambio de productos agrícolas toman la forma de cadenas de valor.

Una definición popular de cadenas de valor las identifica como un arreglo institucional que "describe el rango total de actividades requeridas para llevar un producto o servicio desde su concepción, a través de las fases de producción (...), entrega al productor final hasta deshacerse de él después de su uso" (Kaplinsky y Morris, 2000:4). Una perspectiva más práctica y complementaria a esta definición económico-técnica es la definición de cadena de valor empleada por Goletti (2005,19-20), quien la conceptualiza como las conexiones o vínculos entre los diferentes actores económicos organizados conjuntamente para incrementar la productividad y el valor agregado de sus actividades, garantizar mayores beneficios y mejorar la competitividad de toda la estructura.

Dentro de la cadena, las interacciones e intercambios entre los actores económicos siguen una estructura de gobierno, de roles y reglas, que determinan el nivel de coordinación entre éstos. El gobierno describe cómo los actores de la cadena se relacionan los unos con los otros, así como las reglas que gobiernan sus actividades y relaciones. Gereffi (1999:5) señala que dentro de la cadena usualmente hay un actor (gobernador) que la gobierna y tiene el rol de coordinar las interacciones entre el resto de las partes. El gobierno es establecido para mejorar la eficiencia sistémica, competitividad y valor agregado de la cadena. ${ }^{9}$ Superar 
las limitaciones dentro de la cadena y alcanzar eficiencia sistémica demanda mejoras o upgrading..$^{10}$ En este sentido, el gobernador de la cadena tienela responsabilidad de estimular y apoyar a otros actores de la cadena a superar sus limitantes y ajustar los procesos en un intento por alcanzar la competitividad sistémica a través de mejoras. Trabajando todos conjuntamente, los actores económicos de una cadena logran coordinar sus actividades, reducir sus costos y mejorar la eficiencia (Al-Mudimigh et al., 2004:309). Una coordinación más cercana garantiza mejores flujos de información entre los actores de la cadena, lo que mejora la capacidad de la estructura de ajustarse a nuevas condiciones económicas (Boehlje y Schiek, 1998:1757). Adicionalmente, las ventajas de acciones coordinadas dentro de la cadena residen en los beneficios que los actores derivan de la eficiencia sistémica, explícitamente, de mayores niveles de ganancia que los que podrían obtener si trabajaran por separado (Ruben et al., 2006:17).

A pesar de las ventajas positivas de coordinación entre actores económicos de una cadena, por varias razones éstos no logran coordinarse y trabajar conjuntamente de cara a alcanzar la eficiencia sistémica. ${ }^{11}$ A pesar de que Gereffi (1999:41) señala dos tipos principales de roles de gobierno en la cadena de valor: dirigido por compradores y dirigido por vendedores. En el mundo real, las cadenas rurales en países en desarrollo exhiben bajos o nulos niveles de gobierno, y en otros casos, hay varios puntos de gobiernos desarticulados a lo largo de la cadena (Kaplinsky y Morris, 2000:33). El resultado global se caracteriza por una pobre coordinación, ineficiencia, pocas o nulas mejoras, bajo valor agregado (Goletti, 2005:22) y a su vez, bajos niveles de retornos para los actores de la cadena. La razón central de esta falta de coordinación entre los actores económicos está en los arreglos institucionales pobres establecidos entre los hogares y sus patrones como únicos medios para obtener acceso a las cadenas de valor cuando éstos enfrentan procesos de exclusión.

Las relaciones entrelazadas patrón-clientelistas crean vínculos indirectos -y usualmente débiles- entre los actores económicos, que afectan de manera adversa el gobierno y el desempeño de las cadenas de valor. Van Rooeyn et al. (2001:546) hacen énfasis en el hecho de que, bajo el contexto de cadenas de valor, el valor se pierde cuando un vínculo falla o no funciona efectivamente. Saenz-Segura (2006:5) añade que una relación débil entre hogares productores y procesadores se hace evidente en el funcionamiento de la cadena a través de las etapas sucesivas en términos de calidad, cantidad, tiempo y frecuencia de entrega de producto. Los lazos débiles entre los actores afectan la gobernabilidad de la cadena debido a la imposibilidad o dificultad para establecer reglas y regulaciones concernientes a la producción y el intercambio.

Donde hay lazos débiles los flujos de información necesarios para la coordinación entre actores no están presentes y pueden retrasarse ajustes por el lado de los productores, ocasionando menor calidad y entregas irregulares de producto (Key y Runsten, 1999:386). Una variable clave en este aspecto es el precio pagado a los productores por parte de los procesadores por el producto de los primeros. La presencia de intermediarios comerciales crea situaciones asimétricas de transmisión de precios entre productores y procesadores. Las señales de precios de los productos serán transmitidas completa y más rápidamente a los hogares cuando los precios disminuyan y a su vez, más despacio e incompletas cuando los precios aumenten (Meyer y Von Cramon-Taubadel, 2004:585-6), creando retrasos en 
las respuestas de los hogares -en términos de calidad y entrega- a las variaciones en los precios. A su vez, esta situación crea capacidad en exceso en las plantas de los procesadores para hacer frente a la incertidumbre de los niveles de materia prima entregados (Boehlje y Schiek, 1998:1755). Adicionalmente, y relacionado a la transmisión asimétrica de precios, otra consecuencia de lazos débiles e indirectos entre productores y procesadores es la incapacidad de establecer sanciones ${ }^{12}$ (o premios) en contra del mal (o buen) comportamiento, lo que es clave para el funcionamiento del gobierno de la cadena.

El resultado final de estas situaciones es que los lazos o vínculos entre actores económicos no promueven acciones efectivas para aumentar el valor agregado y alcanzar la eficiencia sistémica y competitividad a través de constantes innovaciones y mejoras (Goletti, 2005:22), lo que a su vez limita los beneficios potenciales que los hogares podrían obtener.

\section{Estudio de caso: la cadena de la leche en Matiguás}

El objetivo de este estudio de caso es evaluar el marco propuesto en base a la realidad encontrada en Matiguás y en su cadena de la leche. Nos hemos enfocado particularmente en la opción de contrato de los hogares rurales dentro de la cadena así como en el desempeño de los sistemas de intercambio basados en las relaciones establecidas entre actores económicos por medio de estos contratos.

La información utilizada para apoyar nuestro marco teórico fue obtenida por medio de una serie de entrevistas semi-estructuradas con actores clave de la cadena durante el verano de 2006. En la primera fase las entrevistas fueron realizadas con un personal selecto del Fondo de Desarrollo Local (FDL) y el Instituto de Investigación y Desarrollo, Nitlapán, ${ }^{13}$ para tener una visión amplia de la cadena de la leche y sus principales actores. En la segunda fase, un total de 10 entrevistas semi-estructuradas fueron realizadas con actores que operan en los diversos niveles de la cadena. Los temas discutidos incluyen: problemas con los canales de comercialización de la leche, fuentes de recursos productivos y membresía en organizaciones formales e informales. Una técnica de muestreo (intencional) fue utilizada para seleccionar a los entrevistados. Dado que era importante tomar en cuenta todas las posibles variables entre los actores de la cadena, se llevaron a cabo entrevistas con actores en diferentes tamaños de finca, ubicación y canales de la cadena de la leche. Durante esta fase de la investigación, con el fin de enriquecer nuestro análisis cualitativo, apuntamos a una muestra estadísticamente representativa de actores e intentamos capturar la diversidad de actores y perspectivas. Sin embargo, reconocemos la necesidad de conducir futuras investigaciones basadas en análisis estadísticos y cuantitativos.

\subsection{Ganado y leche en Matiguás}

Antes de presentar nuestros hallazgos es necesario incluir una descripción general de la cadena de la leche en Matiguás. El municipio es parte del departamento de Matagalpa y se localiza en la zona central de Nicaragua. Matagalpa concentra el 10\% del hato lechero nacional (aproximadamente 62,000 vacas) y produce el 21\% del total de la producción de leche del país, calculada en 230 millones de litros en 2001 (INEC, 2001). En este contexto, la principal actividad económica en Matiguás es la ganadería de doble propósito: leche y 
carne. Aproximadamente 6 de cada 10 hogares en las comunidades rurales tienen por lo menos una cabeza de ganado (Levard et al., 2001:12).

Al igual que en el resto del país, la producción de leche en Matiguás se caracteriza por una fuerte estacionalidad producto de la variación en los niveles de lluvia. ${ }^{14}$ Durante la época seca la falta de lluvia reduce la disponibilidad de pasto para alimentar al ganado, lo que reduce la producción promedio de leche, creando dificultades a los procesadores para obtener suficiente materia prima para los procesos productivos. ${ }^{15}$ Lógicamente, los precios tienden a subir durante este período. La situación cambia durante la época lluviosa, cuando la disponibilidad abundante de lluvias incrementa la disponibilidad de pasturas y la producción de leche aumenta hasta casi duplicarse. La sobre-oferta de leche que tiene lugar durante la época lluviosa viene acompañada de una pronunciada caída de precios para los productores, conocida como el 'golpe lechero'.

La cadena de la leche en Matiguás articula diferentes actores locales y externos alrededor de la producción, comercialización, transformación y consumo de la leche y sus derivados. Los productores se encuentran al inicio de la cadena (ver Ilustración 3). El ordeño se realiza a mano en condiciones más o menos higiénicas, una vez al día, muy temprano por la mañana, usualmente utilizando trabajo familiar y en ocasiones con la ayuda de trabajadores con contratos permanentes. La leche fresca es colocada en depósitos de plástico o acero con capacidad de 40 litros (pichingas), donde queda lista para ser vendida. A nivel de la finca los hogares rurales pueden articularse a diferentes segmentos de la cadena de la leche, como se muestra en la figura. La leche fresca puede ser vendida a (a) centros de acopio, (b) queseros semi-industriales, (c) intermediarios comerciales y (d) queseros artesanales. Dependiendo de las distancias y las relaciones comerciales entre los actores, algunos productores trasladan su leche por sus propios medios -en vehículo o en bestia- hasta los puntos de compra/acopio. Otros hogares, forzados por las largas distancias y/o falta de medios de transporte, se ven obligados a vender su leche a intermediarios que la compran y reciben en puntos específicos definidos a lo largo de una ruta lechera. En general, a los productores se les paga semanalmente por su leche independientemente de a quien la venden. Los controles sobre las cantidades de leche comercializadas son mantenidos por los productores, intermediarios y compradores finales (centros de acopio y queseros). Los controles sobre la calidad son menos rigurosos y dependen del segmento de la cadena de la leche. Los centros de acopio y queseros semi-industriales toman muestras de leche y las someten a pruebas para garantizar que reúna ciertos criterios de calidad. Por otro lado, los queseros tradicionales raramente prueban su leche y usualmente compran toda su materia prima sin tomar en cuenta la calidad. 


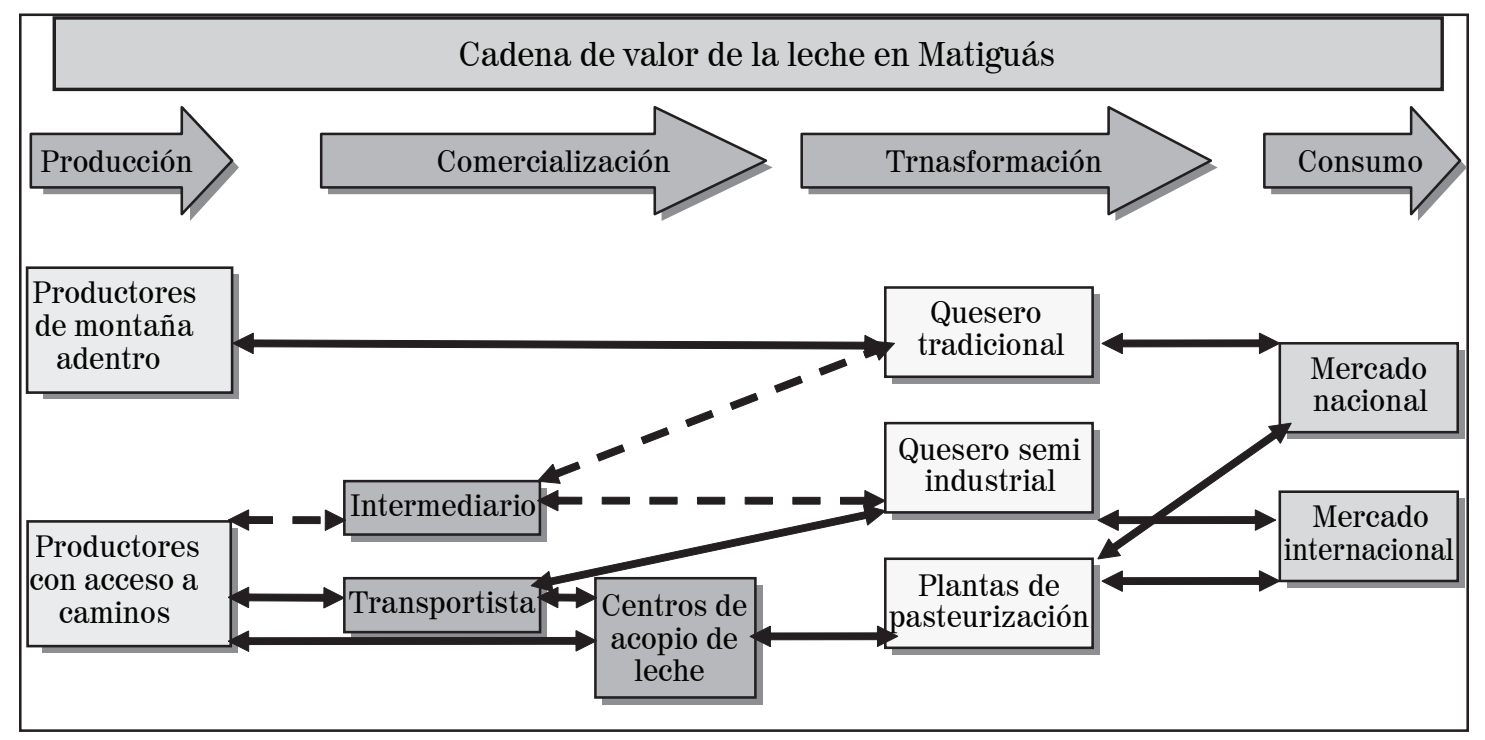

Ilustración 3: Cadena de valor de la leche en Matiguás Fuente: Elaboración propia

Entre los actores de la cadena se establecen diferentes relaciones contractuales que exhiben diferentes niveles de fortaleza y seriedad. Las relaciones entre los productores y los comercializadores pueden ser clasificadas como 'directas' o 'indirectas'. En la Ilustración 3 las relaciones 'indirectas' se representan con líneas punteadas y las relaciones 'directas' con líneas continuas. Cada tipo de relación tiene sus razones de ser y acarrea diferentes consecuencias para los actores que participan y para la cadena como un todo en términos de su funcionamiento y desempeño.

En la fase de comercialización existen dos actores intermediarios que compran leche a los productores para venderla a actores que se encuentran más abajo en la cadena: los intermediarios comerciales (comerciantes) y los centros de acopio. Los intermediarios comerciales actúan como comerciantes-transportistas, compran leche a los productores en fincas y cerca de éstas para luego venderla a los queseros semi-industriales y en otros casos a queseros artesanales. Los intermediarios usan camionetas y camiones para transportar la leche. Cada intermediario tiene el 'derecho' de ofrecer el servicio de recolección de leche por lo menos a lo largo de una ruta lechera. Las rutas lecheras consisten, generalmente, en caminos a comunidades distantes a lo largo de los cuales se establecen varios puntos de recolección y compra. En estos puntos los productores - que traen su leche desde sus fincas en bestias - se reúnen y esperan a los vehículos que recogen la leche del día. La recolección de leche se realiza muy temprano en la mañana (usualmente antes de las 8:00AM) para evitar el calor excesivo que afecta de manera adversa la calidad de la leche.

Los centros de acopio reciben la leche fresca, prueban su calidad en sus laboratorios y luego la refrigeran y guardan para después ser vendida a plantas de pasteurización ubicadas en Managua. Al momento de nuestras entrevistas operaban en Matiguás seis centros de acopio. ${ }^{16}$ Cinco de ellos vendían su leche a plantas de pasteurización ubicadas en Managua (Parmalat 
y Eskimo) y uno de ellos a un quesero semi-industrial ubicado en un departamento al norte de Nicaragua. Tres de los centros de acopio nacieron como cooperativas de productores. Los productores, organizados conjuntamente, fundaron estos centros de acopio con la idea de evitar a los intermediarios comerciales y establecer relaciones directas con los compradores de leche y así resolver el problema de los bajos precios que solían recibir de los intermediarios comerciales, problema exacerbado por la estacionalidad de los precios. ${ }^{17}$ Los productores que venden su leche a centros de acopio usualmente la trasladan por cuenta propia -en vehículo o en bestia- o contratan los servicios privados de transportistas. Generalmente los centros de acopio organizados en cooperativas compran leche solamente de sus miembros. Cuando ocasionalmente compran de productores no miembros, pagan a sus miembros un precio preferencial por su producto. Algunas cooperativas dan asistencia técnica y algunos insumos veterinarios a sus cooperados como parte de los beneficios de ser socio.

En la etapa de transformación la leche es procesada en queso -en queseras tradicionales o semi-industriales- o en leche pasteurizada y otros productos derivados de la leche como yogurt, queso, crema o helado -en plantas pasteurizadoras ubicadas en la capital. Los queseros tradicionales, también llamados 'manteros', compran leche y la transforman -utilizando procesos rudimentarios- en quesos de baja calidad que, por no cumplir con los requerimientos para ser exportados o vendidos en mercados formales, son vendidos en mercados locales o transferidos a mercados informales en la capital. Usualmente los 'manteros' operan en regiones de montaña adentro, en donde no existe ni la infraestructura más básica como agua potable, electricidad y caminos de acceso. Los 'manteros' obtienen su materia prima de productores locales que usualmente por la falta de caminos enfrentan condiciones de aislamiento geográfico y se ven imposibilitados de conectarse a otros circuitos o segmentos de la cadena para vender su leche (Artola y Parrilli, 2002:16).

La leche vendida a los intermediarios comerciales normalmente tiene como destino final dos queseras semi-industriales de capital salvadoreño y hondureño. ${ }^{18}$ En estas plantas, la leche es transformada en diferentes tipos de quesos que son exportados a El Salvador y algunos a los Estados Unidos de Norte América. Los procesos de producción y canales de comercialización son casi enteramentecontrolados por los dueños/socios, quienes resguardan cuidadosamente sus contactos con mayoristas y minoristas en El Salvador y por tanto logran mantener control sobre los canales de comercialización (Artola y Parrilli; 2002:22). La comercialización de leche con estos queseros tiene sus ventajas pues los precios pagados por la leche durante los primeros meses del año tienden a ser altos, convirtiéndolo en un segmento atractivo. A la vez, los requerimientos de calidad tienden a ser menos restrictivos en comparación con aquellos establecidos en los centros de acopio. La desventaja de este segmento es que los precios son muy variables durante el año, especialmente durante la sobre-oferta del 'golpe lechero'. Sin embargo, esta variación no es tanta como en el caso de los intermediarios comerciales y queseros tradicionales.

Las principales plantas de comercialización y compradoras de leche fresca de los centros de acopio son la firma multinacional italiana con presencia en Nicaragua, Parmalat y la planta de pasteurización de capital nacional, Eskimo. Sus plantas se encuentran ubicadas en Managua, donde la leche es transformada en leche fresa y productos lácteos procesados que luego son vendidos en el mercado nacional o exportados a otros países de Centro 
América. Las plantas pasteurizadoras trabajan con una lógica diferente a la de los queseros semi-industriales y artesanales: valoran más la calidad de la leche y pagan por garantizar la misma. ${ }^{19}$ La leche es clasificada en base a su calidad en leche tipo A, B o C, siendo A la leche de alta calidad pagada con una prima positiva, B la leche aceptable y C la leche de baja calidad, en algunos casos rechazada por las plantas pasteurizadoras por su alto nivel de bacterias y acidez (IICA, 2004). Los precios pagados por las plantas de pasteurización tienden a ser más estables (exhiben menor estacionalidad) a los largo del año en comparación con los queseros semi-industriales y en especial en comparación con los intermediarios comerciales y queseros artesanales. Esta situación crea una ventaja de vender leche a los centros de acopio, los cuales han establecidos arreglos (verbales) previos con las plantas de pasteurización por una cuota fija de leche a proveer. El elemento clave aquí es poder garantizar una provisión estable de leche a las plantas de pasteurización en base a la cuota establecida. Si aumenta la provisión de leche producto del 'golpe lechero', la planta de pasteurización continúa comprando leche en los volúmenes establecidos por la cuota y al precio normal (de la época seca), pero la provisión de leche por encima del nivel de la cuota es pagada a un menor precio. Sin embargo, de acuerdo con nuestros informantes, estos precios continúan siendo atractivos cuando se comparan con los precios de los circuitos alternativos, mucho más sensibles a la estacionalidad.

El último eslabón en la cadena son los consumidores. Los destinos finales del queso, la leche y sus derivados son el mercado nacional e internacional (especialmente El Salvador, Honduras y Estados Unidos). Debido a las restricciones de tiempo y recursos no nos fue posible presentar más información detallada sobre este eslabón. A pesar de esto, reconocemos la importancia de saber cuáles segmentos de comercialización son utilizados por los actores que exportan a estos mercados y las consecuencias asociadas en términos de valor agregado.

En el Cuadro 2 presentamos las principales características de los diferentes segmentos de la cadena de la leche en Matiguás. En términos de precios ${ }^{20}$ y estabilidad, los segmentos más interesantes de la cadena son los centros de acopio y queseros semi-industriales, seguidos de los intermediarios comerciales y 'manteros' o queseros tradicionales. Relacionados a los precios están los niveles de calidad de la leche demandados por cada segmento de la cadena.

Cuadro 2: Caracterización de los segmentos de la cadena de la leche Fuente: Elaboración propia basada en entrevistas.

\begin{tabular}{|l|c|c|c|}
\hline Segmento de la cadena & $\begin{array}{c}\text { Precios por } \\
\text { pichinga } \\
(\mathbf{C} \$)\end{array}$ & $\begin{array}{c}\text { Estabilidad } \\
\text { en precios }\end{array}$ & $\begin{array}{c}\text { Calidad de la } \\
\text { leche }\end{array}$ \\
\hline Centros de acopio & $185-190$ & Alto & Alto \\
\hline Queseros semi-industriales & $175-180$ & Medio & Alto - Medio \\
\hline Intermediarios comerciales & $140-150$ & Medio & Alto - Medio \\
\hline Queseros tradicionales & $<130$ & Bajo & Bajo \\
\hline
\end{tabular}


En cuanto a los precios pagados por la leche y su estabilidad, es claro que cualquier productor estaría mucho mejor si vendiese su leche a los centros de acopio. Pero por diversas razones no todos los hogares pueden o quieren tener acceso a este segmento de la cadena. Su segunda mejor opción incluye a los queseros semi-industriales y a los intermediarios comerciales. Los hogares rurales son diferentes, así como lo son las limitaciones y obstáculos que enfrentan. En este sentido, hemos de hacer diferencia entre aquellos hogares rurales que son excluidos de la cadena producto de la falta o inexistencia de infraestructura que permita realizar la transacción, y aquellos hogares que son excluidos por la falta de servicios de apoyo a los procesos de producción y comercialización -nos referimos específicamente al crédito. En este último grupo se encuentran los hogares que participan de la cadena y que podrían incrementar su producción pero no lo hacen porque no cuentan con recursos apropiados que les permitan hacerlo. También están aquellos cuyo nivel de producción es lo suficientemente alto pero no pueden conectarse con el siguiente segmento de la cadena por su incapacidad de mejorar su producción y calidad debido a la falta de recursos.

En Matiguás, la falta de infraestructura, especialmente caminos, puede excluir completamente a algunos actores de la cadena de los principales segmentos de la misma. El municipio enfrenta serias deficiencias que en algunos casos son agravadas por la extensión geográfica de su territorio y la dispersión de la población a lo largo de éste. En Matiguás solamente existe una carretera pavimentada que cruza la municipalidad de Este a Oeste. Dada la falta de infraestructura, algunas comunidades se encuentran geográficamente aisladas y experimentan una completa falta de caminos de acceso. Esta situación limita la capacidad de los productores para conectarse con los segmentos más interesantes de la cadena de la leche. Este es el caso en las comunidades sureñas de Lagarto Colorado, El Santolar, Likia Abajo y el Salto de la Olla, así como para las comunidades de San José de las Mulas y El Zabalete, ubicadas en la región Norte del municipio. Dado el carácter perecedero de la leche, para los hogares de estas comunidades, la falta de caminos se convierte en un obstáculo que imposibilita el transporte y venta de leche a intermediarios o centros de acopio. ${ }^{21}$ Es por esta razón que algunos hogares no tienen otra opción que vender su leche a los queseros tradicionales locales ubicados en las entrañas de las montañas, quienes transforman la leche en queso tradicional usualmente vendido en los mercados a través de circuitos de comercio informal, donde los requerimientos de calidad están casi ausentes.

Para los productores, esto implica una reducción de los precios que podrían estar recibiendo debido a que la falta de infraestructura limita sus posibilidades de conectarse con otros segmentos de la cadena de la leche donde los precios pagados por ésta son más altos. Adicionalmente, el aislamiento geográfico crea una estructura de mercado de monopsonio bajo la cual el quesero, siendo el único comprador de leche en la zona, puede extraer mayores beneficios en detrimento de los productores locales. Uno de nuestros informantes expresó que en las comunidades aisladas durante la época lluviosa, los 'manteros' pueden llegar a un precio tan bajo que es equivalente a un $25 \%$ del precio pagado por los queseros semiindustriales y centros de acopio.

En otras áreas del municipio, caminos secundarios no pavimentados comunican la carretera principal con algunas comunidades rurales. Pero los hogares que habitan en estas comunidades también enfrentan dificultades por las pobres condiciones en las que 
se encuentran estos caminos, en especial durante la época lluviosa. Sin embargo, a lo largo de estos caminos, rutas lecheras son establecidas por intermediarios o transportistas que trasladan la leche desde las fincas de los productores y/o puntos de recolección hasta los queseros semi-industriales y centros de acopio ubicados en el casco urbano y a lo largo de la carretera pavimentada. No obstante, a pesar de la existencia de rutas lecheras, algunos productores enfrentan problemas para vender su leche a los centros de acopio y queseros semi-industriales, donde los precios pagados por la leche son más altos.

Los hogares enfrentan el problema de la falta de provisión y/o acceso a servicios necesarios para apoyar la producción y comercialización de la leche. En Matiguás, la mayor parte de la provisión de servicios se encuentra concentrada en la ciudad (Levard et al., 2001:12), lo que junto con la falta de y pobres condiciones de los caminos de acceso, limita la capacidad de los hogares de acceder a éstos. Esta falta de acceso a servicios -específicamente crédito - crea exclusión económica para algunos hogares de ciertos segmentos de la cadena de la leche. Normalmente, los productores necesitan capital de trabajo para comprar insumos veterinarios para el ganado, así como servicios veterinarios de calidad para chequeos regulares o inseminación artificial, o para mantener o reemplazar algunas herramientas y equipos usados durante la producción (cercas de alambre, picadoras de pasto) y comercialización (pichingas) de la leche. Los productores en mejor posición no tienen la necesidad de buscar crédito, pues sus posibilidades les permiten auto-financiarse estos recursos y servicios. Pero la mayoría de los productores no tiene dicha capacidad y debe recurrir a préstamos para capital de trabajo.

Por otro lado, ser capaz de vender a los segmentos más altos de la cadena de la leche requiere de niveles apropiados de producción y de la implementación de técnicas de ordeño limpio que demandan recursos financieros para la inversión. El primer obstáculo -y poco evidente - al momento de vender leche a los segmentos más altos de la cadena es lograr alcanzar los niveles mínimos de producción dadas las deseconomías de escala en el transporte y los costos fijos de membresía en los centros de acopio. Normalmente, la entrega de leche en los centros de acopio se realiza en pichingas con una capacidad de 40 litros. Los hogares cuya capacidad se encuentra por debajo de este nivel (según el promedio de litros de leche por vaca por día, se necesitan por los menos 12 vacas $^{22}$ ) quedan excluidos de los centros de acopio por causa de las deseconomías de escala y los costos de transacción. Adicionalmente, el transporte de la leche debe ser realizado en pichingas de acero cuyo costo en el mercado local ronda los US\$ 80.00 y por cada 40 litros es necesario tener dos pichingas. ${ }^{23}$ El acero es un material apropiado para el manejo de la leche porque retiene menos bacterias que afectan la calidad de la misma. Con el fin de sacar provecho total al contenedor de leche, los hogares deben asegurar que pueden llenar una pichinga de 40 litros con su producción diaria. Relacionado a este aspecto también se encuentran los costos de transporte. Un costo fijo de 10 a 20 córdobas es cobrado por el traslado de una pichinga, independientemente de la cantidad de leche que ésta contenga. El traslado de pichingas a medio llenar implica un costo de oportunidad para los pequeños productores que en muchos casos deben pagar por el transporte ellos mismos. El costo del litro de leche transportado se hace mayor en la medida en que la pichinga contenga y transporte una cantidad menor de leche. Los productores deben asegurarse de llenar la pichinga hasta su capacidad total para poder distribuir los costos fijos de transporte entre más litros de leche producidos y comercializados. 
Ahora bien, para garantizar la calidad de la leche e identificar oportunamente problemas con el fin de buscarles solución, los centros de acopio trabajan con una lógica basada en una relación directa y cercana con los productores. Garantizar niveles similares de calidad de leche entre todos los productores miembros de un centro de acopio es clave para asegurar cuotas de venta con las plantas pasteurizadoras. En muchos casos, los centros de acopio sólo cuentan con un tanque de recolección donde la leche de todos los productores es mezclada y almacenada. Esta situación crea un problema si la leche buena de productores 'limpios' se combinan con leche mala de productores 'sucios'. Es el promedio de la calidad de la leche la que determina la habilidad de un centro de acopio para seguir trabajando y supliendo leche a las plantas de pasteurización, las cuales ofrecen precios más altos y estables a lo largo del año. Por esta razón, todos los productores miembros de un centro de acopio tienen la obligación de cumplir con unos estándares higiénicos mínimos de ordeño, manejo y traslado de leche. ${ }^{24}$ El ordeño limpio implica la adopción de ciertas técnicas y la inversión en infraestructura y equipos para ordeño en la finca (sala de ordeño, piso embaldosado, abundante agua y pichingas de metal para el transporte de la leche) que requieren capital de inversión de largo plazo.

Además del capital de trabajo e inversión necesarios para que los productores puedan aumentar sus niveles de producción y adoptar técnicas de ordeño limpio, los hogares que deseen vender su leche a los centros de acopio necesitan recursos para cubrir los costos de asociación o membresía. Este costo constituye una precondición para poder vender a este segmento de la cadena. Al tiempo de nuestro trabajo de campo, el costo de membresía rondaba entre 3,000 y 4,000 córdobas (aproximadamente US\$200.00) por pichinga de 40 litros a comercializar. Este pago se realiza una sola vez y el dinero es utilizado para invertir en la infraestructura del acopio, particularmente en el edificio y los equipos de enfriamiento y almacenaje.

Cuando los hogares no logran asegurar los recursos necesarios para aumentar o mejorar la producción, son excluidos de los potenciales beneficios derivados de tomar parte en la cadena de valor. Por ejemplo, uno de nuestros entrevistados consideró alto el costo de membresía y fuera del alcance de algunos productores. Como consecuencia de esto, el entrevistado vendía su leche a uno de los queseros semi-industriales de la zona. Adicionalmente, la falta de acceso a servicios financieros implica la ausencia de seguros en caso de emergencias causadas por los riesgos e incertidumbres asociados con las actividades agropecuarias. Bajo estas circunstancias, los hogares se ven forzados a encontrar otras formas de conectarse con la cadena de la leche que les permitan a la vez obtener los recursos (financieros) necesarios así como algún tipo de seguro sustituto. El resultado general es el uso de arreglos contractuales inmersos en relaciones entrelazadas extractivas patrón-clientelistas que otorgan sustitutos de seguros y acceso a sistemas de intercambio, pero bajo términos desfavorables.

Los hogares implementan relaciones entrelazadas cuando acuerdan vender su leche a un intermediario comercial a cambio de recibir beneficios como acceso a mercados, insumos y especialmente crédito (como capital de trabajo o préstamos de emergencia). Las entrevistas reflejaron que es una práctica común de los intermediarios, un quesero semi-industrial y un centro de acopio privado prestar dinero a los productores como adelantos por la venta de leche. La cantidad total del préstamo puede llegar a corresponder al valor en ventas 
de leche de dos semanas. No se cobran intereses por el préstamo pero los productores pagan un costo indirecto debido a que reciben un precio inferior por su leche comparado al establecido en el mercado. Adicionalmente, los productores obtienen protección (seguro) en la medida en que su relación con el intermediario se asemeja a una relación patróncliente. Los intermediarios extienden créditos de emergencia a los productores en cualquier momento para enfrentar cualquier problema (enfermedad, servicios veterinarios, etc.), así como servicios adicionales (los intermediaros comúnmente ayudan a los productores que trabajan con ellos con aventones a los miembros de la familia o trayendo del casco urbano ciertos bienes de consumo a los productores que habitan en las comarcas). Contrario a los intermediarios, los centros de acopio no otorgan adelantos por la venta de leche ni tampoco extienden créditos de emergencia a los productores.

Pero no todos los hogares establecen relaciones entrelazadas con los intermediarios comerciales. Encontramos que un comerciante en una misma ruta lechera se puede comportar solamente como transportista para algunos hogares y como intermediario para otros. En la misma ruta lechera, algunos hogares que ya tenían arreglos contractuales con algún centro de acopio o quesero semi-industrial, hacen uso de los servicios de transporte pagando por el traslado de cada pichinga. En otros casos, como alternativa para tener acceso a la cadena de la leche, los hogares sin estos tipos de arreglos comerciales tienen que vender su leche a los intermediarios comerciales, quienes la compran y recolectan en grandes barriles plásticos color azul. En el primer caso, la relación entre productores y centros de acopio/ queseros semi-industriales es directa y no afecta los incentivos, pues el productor es pagado por la (alta) calidad de la leche que él mismo entrega. Los hogares que venden a centros de acopio o queseros semi-industriales establecen relaciones directas con los compradores, lo cual implica un vínculo fuerte entre ambas partes concerniente a la producción, entrega y pago de la leche. Este vínculo directo permite una relación de coordinación cercana necesaria para alcanzar altos niveles de calidad y precios, que no puede ser alcanzada con los intermediarios comerciales.

Los hogares que venden su leche a intermediarios comerciales establecen relaciones indirectas con sus compradores finales. Los intermediarios crean vínculos débiles que dan lugar a problemas en los flujos de información relacionados a la calidad dela leche, condiciones de entrega y precios a pagar. Dada la presencia de los intermediarios comerciales, los compradores no pueden coordinar la producción y comercialización de leche directamente con los productores. En este caso, el 'gran barril azul' usado para el transporte de la leche no permite diferenciar y remunerar de acuerdo a la calidad de la leche entregada. De hecho, todos los productores reciben un menor precio (correspondiente a una leche de calidad C) y ningún productor tiene incentivos para tener cuidados de higiene al momento del ordeño. Los intermediarios comerciales luego venden esta leche a algunos queseros, cuyos procesos rudimentarios de producción de queso no requieren de leche de alta calidad.

Finalmente, hemos de añadir que encontramos situaciones en las que, a pesar de que los productores reconocen las ventajas y beneficios de organizarse en cooperativas y tienen los recursos necesarios para hacerlo, deciden auto-excluirse de este tipo de organizaciones debido a sus percepciones personales acerca de la cooperativa como forma de organización. Algunos productores entrevistados se refirieron a experiencias de organizaciones del 
pasado que fracasaron; cooperativas que al momento de su desintegración causaron pérdidas a sus miembros. Estas experiencias fueron señaladas como la principal razón para no querer organizarse en cooperativas. Uno de los entrevistados expresó que "existe mucha desconfianza en las organizaciones y sus juntas directivas, porque en el pasado todas demostraron que los miembros de la junta directiva se comportaron de forma oportunista... la gente tiene miedo de volver a perder". Otra razón importante para no querer organizarse en cooperativas es porque éstas están asociadas con los gobiernos de izquierda. Durante los ochenta, el gobierno sandinista de izquierda forzó a muchos productores a organizarse en cooperativas controladas por el Estado. Durante este período, Matiguás fue unas de las zonas donde los productores se opusieron fuertemente al régimen de aquel entonces, considerado hostil a los intereses (individuales) de los campesinos y lógicamente opuesto a sus formas de organización. Después de las elecciones de 1990, en las que el gobierno sandinista perdió el poder, el gobierno saliente promovió la legalización de la tierra en control de las cooperativas a favor de los miembros de las mismas. Actualmente, persiste un estigma entre los productores de Matiguás sobre las cooperativas considerando a muchas de éstas como sinónimo de control externo, oportunismo y ‘regalo’ y tal vez, peor aún, 'sandinismo'. Debido a estas percepciones de las cooperativas, muchos productores se rehúsan a formar parte de una.

En términos de los precios pagados por la leche, está claro que los productores estarían mejor si cambiasen el segmento de comercialización de su leche. Pero se encuentran imposibilitados de hacerlo por falta de acceso a recursos y por su relación de dependencia con los intermediarios. Cambiar su situación actual -o elección de contrato- podría implicar perder su acceso al mercado, insumos (crédito) y beneficios (protección o seguro). En otros casos, productores que tienen capacidad para organizarse pueden simplemente decidir auto-excluirse de los segmentos más beneficiosos de la cadena. El resultado final de los problemas que enfrentan los productores en la cadena de valor es que el potencial productivo del sector lechero en Matiguás no es aprovechado y explotado plenamente (Levard $e t$ al., 2001:67), así como tampoco lo son los beneficios que los hogares articulados a la producción y comercialización de la leche, podrían obtener.

\section{Conclusiones}

A lo largo de este artículo se ha discutido que aún en presencia del mercado dinámico de la leche en el municipio de Matiguás, los hogares enfrentan dificultades para articularse a éste y se ven limitados de disfrutar los posibles beneficios que podrían obtener del mismo. La situación es evidente cuando analizamos el desempeño de la cadena de la leche. La falta de infraestructura y de servicios de apoyo al intercambio limita el desempeño de la cadena y a su vez bloquea el acceso de los hogares a la misma, creando procesos de exclusión o permitiendo el acceso a la cadena bajo condiciones desfavorables. En este contexto, algunos hogares toman parte en transacciones entrelazadas patrón-clientelistas como la única manera para obtener acceso a la cadena de la leche cuando enfrentan procesos de exclusión económica (falta de recursos y costos de transacción) y social. En otros casos, los hogares que no sufren de ningún tipo de exclusión, aun así pueden optar por auto-excluirse de arreglos contractuales potencialmente beneficiosos que pueden ser evaluados como desfavorables por éstos dadas sus percepciones de la realidad basada en modelos imperfectos y subjetivos. 
Estas situaciones causan la segmentación de la cadena de la leche en donde los diferentes hogares operan en diferentes canales para conectarse a la cadena, cada uno con su propia lógica productiva y comercial, y desempeño distributivo y participativo.

Adicionalmente, reconocemos que nuestro diagnostico sobre las oportunidades y limitantes de los medios de vida de los hogares rurales (pobres) en presencia de una fuerte dinámica en la cadena de la leche, es preliminar y exploratorio. Reconocemos la necesidad de investigación empírica sobre las opciones de contrato de los hogares. Hasta ahora, mucha de la literatura económica concerniente a la opción de contrato en la agricultura se ha enfocado en las transacciones rurales entrelazadas, especialmente los contratos de tenencia de tierra que aplican modelos 'agente-principal' (Mitra, 1983; Chaudhuri y Gupta, 1995; Ghatak y Pandey, 2000; Cheung, 1969; Agrawal, 1999; Allen y Luek, 1999; Eswaran y Kotwal, 1985, por mencionar algunos) para tratar temas relacionados a los costos de transacción, riesgo, incentivos e imperfecciones en los mercados de factores. Otros estudios (Abucheli, 2006; Saenz-Segura, 2006; Szabo y Bardos, 2005; Ferto y Gabor, 2002; Poole et $a l ., 1998)$ se han enfocado en la elección de contrato de los productores concerniente a los canales de comercialización de sus productos, haciendo uso únicamente del enfoque de costos de transacción. La investigación futura de este tema debe ir más allá de los enfoques económico-técnicos. Debe intentar incluir adicionalmente variables socio-culturales que en parte también explican las opciones de contratos de los hogares rurales. Solamente de esta manera podremos aspirar a comprender más ampliamente las estrategias de vida de los hogares (rurales) para diseñar e implementar políticas adecuadas dirigidas a remover los obstáculos y potenciar las oportunidades de estrategias de vida.

\section{Notas}

1 Un ejemplo común de sistemas de intercambio podría ser un mercado; otros incluyen arreglos de intercambio fuera del mercado, como algunas cadenas de valor y/o integración vertical (jerarquía), o configuraciones informales de intercambio fuera del mercado, como las transacciones entrelazadas.

2 En lo que sigue del artículo utilizaré el término 'estructuras de gobierno'.

3 Williamson identifica estructuras de gobierno principales para llevar a cabo las transacciones: el mercado clásico (transacciones simples en el mercado), jerarquía (integración vertical) e híbrido (una combinación de las dos anteriores).

4 El capital social se refiere a redes (horizontales y verticales) y a organizaciones (formales e informales) -ambas expresiones de relaciones sociales (estructuras sociales)- , así como a vínculos (acciones/interacciones a lo interno de las estructuras) establecidos entre las personas (Woolcock y Narayan, 2000). El capital social emerge de las relaciones de un individuo con el resto, y su ventaja radica en ser parte de redes y organizaciones que le permiten recibir beneficios como el acceso a recursos y la mitigación de los costos de transacción. Como una buena ilustración del capital social, ver la investigación de Brautigam (1997) acerca del desarrollo industrial en Nigeria.

5 El crédito puede funcionar como sustituto de un seguro en caso de que los hogares fuesen golpeados por una emergencia (Diagne y Zeller, 2001), actuando como un seguro expost de corto plazo para suavizar el ingreso y el consumo.

6 Por el lado positivo, relaciones entrelazadas y patrón-clientelistas tienen un efecto de minimización de costos de transacción. Las múltiples transacciones entre las mismas partes por un período de varios años por medio de bienes y servicios, sirve como un mecanismo para reducir los costos de transacción dado que los costos de conseguir información y garantizar el cumplimiento del contrato son comunes al resto de las transacciones (Hayami y Kikuchi, 1982).

7 El carácter perecedero de los productos agrícolas incrementa la complejidad de las transacciones; da lugar a incertidumbre por parte de los compradores (asegurar calidad y oferta confiable) y consumidores en la medida en que la incertidumbre de precios aumenta producto de la variación en la calidad, sobre la cual los precios a pagar y recibir son establecidos (Hobbs y Young, 1999). 
8 Una cadena de valor ofrece ventajas en la coordinación de la producción e intercambio en la medida en que facilita adaptaciones coordinadas y cooperación cercana entre los actores envueltos en la secuencia de relaciones englobadas en comparación con las transacciones puras de mercado. Adicionalmente, evita la falta de flexibilidad y los altos costos de administrar una industria completamente integrada verticalmente.

9 Los actores más fuertes de la cadena han comprendido que las actividades de las que son totalmente responsables solamente representan una parte del total de actividades y procesos necesarios para desarrollar un producto y llevarlo a los consumidores. A menos que éstos se vuelvan gobernadores de la cadena para obtener mayores niveles de eficiencia a lo largo de toda la estructura, poco pueden hacer para ser más competitivos y generar mayor valor agregado (Kaplinsky, 2000).

10 Upgrading se refiere a innovaciones hechas para alcanzar mayores niveles de valor agregado; deben ser entendidas como mejoras marginales en productos y/o procesos que resultan nuevos a los actores de la cadena y que permiten a la estructura como un todo continuar y mantener su posición competitiva bajo un ambiente de constantes cambios (Giuliani et al., 2003).

11 Dado que la competencia en los sistemas de intercambio no siempre es perfecta, el supuesto de Williamson de formas organizacionales de intercambio innovadoras que minimizan los costos no siempre se mantiene automáticamente bajo presiones competitivas.

12 Las sanciones son generalmente negativas y van dirigidas a los transgresores, pero también pueden ser positivas para premiar el cumplimiento de reglas y normas (Kaplinsky y Morris, 2000).

13 Ambas instituciones cooperan de cerca con productores rurales en la zona de Matiguás.

14 En Nicaragua existen dos grandes estaciones climáticas, cada una con una duración aproximada de seis meses. La época seca se extiende entre los meses de noviembre y abril y la época lluviosa entre mayo y octubre.

15 Por ejemplo, ambas queseras semi-industriales de la zona experimentan reducciones de entre $12.5 \%$ y $25 \%$ en el acopio de leche durante la época seca del año.

16 Los seis centros de acopio identificados durante el estudio son: San José, San Martín y 24 de Junio (que son cooperativas de productores), y El Porvenir, San Francisco y Agrolac (de propiedad privada).

17 Organizados en cooperativas los productores de leche pueden invertir en infraestructura de enfriamiento y almacenaje de leche, añadiendo mayor valor a su producto y evitando las presiones de más abajo en la cadena para reducir los precios (Lazzarini et al., 2001).

18 A pesar de nuestros varios intentos no conseguimos entrevistar a los dueños de estas empresas. La información acá presentada fue mas que todo obtenida por medio de triangulación con informantes y repaso literario. Los comerciantes salvadoreños suelen resguardar celosamente la información concerniente a sus proveedores, sus rutas de exportación y contactos comerciales.

19 Hace varios años las pasteurizadoras solían pagar en base a la calidad del producto que recibían. Pero en la medida en que los productores comenzaron a sospechar que la clasificación de la leche no era utilizada para pagar más por la leche de mejor calidad sino como una excusa conveniente para aplicar políticas arbitrarias reductoras de precios en detrimento de los productores, el sistema de clasificación fue suspendido por su falta de legitimidad local. Sin embargo, este circuito de comercialización de leche todavía tiende a exigir niveles estándares mínimos de calidad por la leche proveída.

20 Los precios recibidos por los productores pueden variar en dependencia de quién asuma los costos de transporte (intermediarios o productores), que oscilan entre 10 y 20 córdobas por pichinga, dependiendo de las distancias y condiciones de los caminos.

21 La leche fresca es un producto sumamente perecedero. Una vez que fue ordeñada la vaca, la leche requiere de refrigeración dentro de las primeras dos horas como máximo. La falta de refrigeración da lugar a la proliferación de bacterias y consiguiente deterioro de la calidad.

22 Basado en el promedio nacional de producción de 3.5 litros por vaca por día (IICA, 2001).

23 Una es utilizada para el traslado de la leche del día y es devuelta hasta la mañana siguiente, cuando se intercambia la vacía del día anterior por la llena con la leche ordeñada ese mismo día.

24 El transporte de leche es realizado en pichingas de acero 0 aluminio identificables con un número correspondiente a cada productor para poder identificar el origen de la leche si se presentan problemas (contaminación/bacterias) durante el muestreo y prueba de la misma. 


\section{Referencias bibliográficas}

AGRAWAL, P. (1999). "Contractual Structure in Agriculture”. En Journal of Economic Behavior and Organization, Vol. 39, pp. 293-325.

AL- MUDIMIGH, S. et al (2004). "Extending the Concept of Supply Chain: The Effective Management of Value Chains". En International Journal of Production Economics, Vol. 87, No. 3, pp. 309-320.

ALLEN, W. et al (1999). "The Role of Risk in Contract Choice". En Journal of Laws, Economics and Organization, Vol. 15, No. 3, pp. 704-736. Oxford.

ARTOLA, N. \& PARRILLI, D. (2002). Cadenas productivas: Lecciones de la experiencia internacional y regional: El despegue del cluster de productos lácteos de Boaco y Chontales, Nicaragua. Managua: Instituto de Investigación y Desarrollo, Nitlapan - UCA.

BARRET, C. et al. (2001). "Nonfarm Income Diversification and Household Livelihood Strategies in Rural Africa: Concepts, Dynamics and Policy Implications”. En Food Policy, Vol. 26, No. 4, pp. 315-331.

BASTIAENSEN, J. et al. (2002). Poverty, Institutions and Interventions - a Framework for an Institutional Analysis of Poverty and Local Anti-Poverty Interventions, Discussion Paper 2002-06: Institute of Development Policy and Management. Antwerp University, Antwerp, Belgium

BASTIAENSEN, J. et al. (2005). "Poverty Reduction as a Local Institutional Process". En World Development, Vol. 33, No. 6, pp. 979-993.

BANCO CENTRAL DE NICARAGUA (2006). Índice Mensual de Actividad Económica. Managua: Disponible en: http://www.bcn.gob.ni/estadisticas/default.shtm [consultado en marzo de 2007]

BARDHAN, P. \& Udry, C (1999). Development Microeconomics. Oxford: Oxford University Press. 1era edición

BINSWANGER, H. et al. (1986). "Behavioural and Material Determinants of Production Relation in Agriculture”. En Journal of Development Studies, Vol. 22, No.3, pp. 503539.

BOEHLJE, M. et al. (1998). "Critical Success Factors in a Competitive Dairy Market". En Journal of Dairy Science, Vol. 81, No. 6, pp.1753-1761.

BRAUTIGAM, D. (1997). "Substituting for the State: Institution and Industrial Development in Eastern Nigeria”. En World Development, Vol. 25, No.7, pp. 1063-1080.

CHAUDHURI, S. et al. (1995). "Price Uncertainty and Credit-Product Interlinkage: An Extension of the Analysis of Gangopadhyay and Sengupta". En The Journal of International Trade and Economic Development, Vol. 4, No.1, pp. 93-113.

CHEUNG, S. (1969). "Transaction Costs, Risk Aversion, and the Choice of Contractual Arrangements". En Journal of Laws and Economics, Vol. 12, No. 1, pp. 23-42.

DAVIS, E. \& NORTH, D. (1971). Institutional Change and American Economic Growth. Cambridge: Cambridge University Press, 1era edición.

DIAGNE, A. et al. (2001). Access to Credit and its Impact on Welfare in Malawi. Research Report No 116. Washington, D.C.: International Food Policy Research Institute.

DFID. (1999). "Framework of Sustainable Livelihoods", Sustainable Livelihood Guidance Sheets. Abril 1999. Londres. Disponible en: http://www.smallstock.info/issues/sust_liv. htm\#guidance [consultado en abril de 2006] 
DORWARD, A. \& KYDD, J. (2005). Making Agricultural Market Systems Work for the Poor: Promoting Effective, Efficient and Accessible Coordination and Exchange. Londres: London Imperial College, febrero de 2005. Disponible en: http://www.dfid.gov. uk/news/files/trade news/adb-workshop [consultado en mayo de 2005]

EISENSTADT, S. et al. (1980). "Patron-Client Relations as a Model of Structuring Social Exchange". En Comparative Studies in Society and History, Vol. 22, No. 1, pp. 4277.

ELLIS, F. (2000). Rural Livelihoods and Diversity in Developing Countries. Oxford: Oxford University Press, 1era edición.

ESWARAN, M. et al. (1985). "A Theory of Contractual Structure in Agriculture". En The American Economic Review, Vol. 75, No. 3, pp. 352-367.

FERTO, I. et al. (2002). "The Choice of Supply Channels in Hungarian Fruit and Vegetable Sector". En Economics of Contracts in Agriculture. Second Annual Workshop, Annapolis, MD, 21-23 julio.

GANGOPADHYAY, S. et al. (1987). "Small Farmers, Moneylenders and Trading Activity". En Oxford Economic Papers, New Series, Vol. 39, No. 2, pp. 333-342.

GEREFFI, G. (1999). "A Commodity Chains Framework for Analysing Global Industries". Background Notes for Workshop on Spreading the Gains from Globalisation, Sussex: Institute of Development Studies. Disponible en: www.ids.ac.uk/ids/global/conf/ wkscf.html [consultado en mayo de 2002]

GHATAK, M. et al. (2000). "Contract Choice in Agriculture with Joint Moral Hazard in Effort and Risk". En Journal of Development Economics, Vol. 63, pp. 303-326.

GIULIANI, E. et al. (2005). "Upgrading in Global Value Chains: Lessons from Latin American Clusters”. En World Development, Vol. 33, No. 4, pp. 549-573.

GOBIERNO DE NICARAGUA. (2005). Plan Nacional de Desarrollo. Managua, noviembre de 2005. Disponible en: www.siteresources.worldbank.org [consultado en septiembre de 2006]

GOLETTI, F. (2004). The Participation of the Poor in Agricultural Value Chains. A draft Research Program Proposal. Ha Noi, Viet Nam. Agrifood Consulting International for Making Markets Work Better for the Poor Project, Asian Development Bank.

GOLETTI, F. (2005). Agricultural Commercialization, Value Chain and Poverty Reduction. Making Markets Work Better for the Poor, Discussion Paper No. 7. Ha Noi, Viernam, enero de 2005. Disponible en:

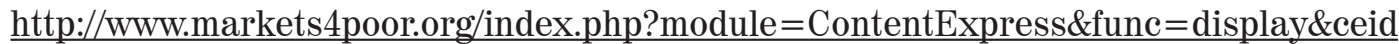
$=55 \&$ meid $=37 \quad$ [consultado en junio de 2006]

HAYAMI, Y. \& OTSUKA, K. (1993). The Economics of Contract Choice, An Agrarian Perspective. Oxford: Clarendon Press, 1era edición.

HAYAMI, Y. \& MASAO, K. (1982). Asian Village Economy at the Crossroads. An Economic Approach to Institutional Change. Baltimore: John Hopkins University Press, 1era edición.

HOBBS, J. et al. (1999). Increasing Vertical Linkages in Agrifood Supply Chain: A Conceptual Model and some Preliminary Evidence, Research Discussion Paper No.35, University of Saskatchewan, agosto.

INSTITUTO INTERAMERICANO DE COOPERACIÓN A LA AGRICULTURA. (2004). Estudio de la Cadena de Comercialización de la Leche. Managua: Edición IICA.

INEC. (2001). Tercer Censo Nacional Agropecuario. Managua, marzo de 2001. Disponible 
en: http://www.inec.gob.ni/ [consultado en septiembre de 2003].

JOHNSON, A. (2004). Making Market Systems Work Better for Poor Communities. Discussion Paper 4. Ha Noi, Vietnam, noviembre. Disponible en: http://www.markets4poor.org/index. php? module $=$ ContentExpress \&func $=$ display\&ceid $=55 \&$ meid $=37$. [consultado en abril de 2006].

JOHNSON, A. et al. (2005). Making Market Systems Work Better for the Poor; An Introduction to the Concept. Discussion Paper, Londres: Department for International Development.

KAPLINSKY, R. et al. (2000). A Hand Book for Value Chain Research. Disponible en: http:// www.acdivoca.org/acdivoca/. [consultado en enero de 2005].

KAPLINSKY, R. (2000). "Globalization and Unequalisation: what can be learned from value chain analysis?” En Journal of Development Studies, Vol. 37, No. 2, pp. 117-146.

KEY, N. et al. (1999). "Contract Farming, Small Holoders and Rural Development in Latin America: The Organization of Agroprocessing Firms and the Scale of Outgrower Production”. En World Development, Vol. 27 No.2 pp.381-401.

LAZZARINI, S. et al. (2001). "Integrating Supply and Network Analysis: The Study of Netchains". En Journal on Chain and Network Science, Vol. 1, No.1, pp.7-22.

LEVARD, L. et al. (2001). Municipio de Matiguás, potenciales y limitantes del desarrollo agropecuario. Cuaderno de Investigación \#11, Nitlapán. Managua: UCA Publicaciones 1era edición.

MEYER, J. et al. (2004). "Asymmetric Price Transmission: A survey”. En Journal of Agricultural Economics, Vol. 55, No. 3, pp. 581-611.

MITRA, P. (1983). "A Theory of Interlinked Rural Transactions". En Journal of Public Economics, Vol. 20, No. 2, pp. 167-191.

NORTH, D.C. (1990). Institutions, Institutional Change and Economic Performance. Cambridge: Cambridge University Press. 1era edición.

POOLE, D. et al. (1998). "Formal Contracts in Fresh Produce Markets". En Food Policy, Vol. 23, No. 2, pp.131-142.

RICHARD, M. (2005). Rural Poverty Reduction in Central America: Trends, Challenges and the Role of Rural Services. Keynote paper for the "International Conference Rural Poverty Reduction in Central America: Strengthening Technical, Business, Development and Financial Services". San José: CATIE, abril 11-13.

RUBEN, R. et al. (2006). "Agro-food Chains and Networks for Development". En Ruben, R.; Slingerland, M. \& Nijhoff, H. (Eds). Agro-food Chains and Networks for Development. The Netherlands: Springer, 1era edición.

SAENZ-SEGURA, F. (2006). Contract Farming in Costa Rica: Opportunities for Smallholders?. Tesis de doctorado. Wageningen: Wageningen University. 328p.

SCOTT, J. (1972). "The Erosion of Patron-Client Bonds and Social Change in Rural Southeast Asia”. En Journal of Asian Studies, Vol. 32, No.1, pp. 5-37.

SZABO, G.et al. (2005). Vertical Coordination by Contracts in Agribusiness: An Empirical Research in the Hungarian Dairy Sector. Conference on "Transition in Agriculture - Agricultural Economics in Transition II”, Institute of Economics, Hungarian Academy of Science.

VANROOYEN, C.et al.(2001). "Creatinga Chain Reaction-a KeytoIncreased Competitiveness in South African Agribusiness”. En South African Journal of Economics, Vol. 69, No. 3 , pp.529-549. 
VAN DER MEER, C. (2006). "Exclusion of Small-Scale Farmers from Coordinated Supply Chains: Market Failure, Policy Failure or Just Economies of Scale?”. En Ruben, R.; Slingerland, M. \& Nijhoff, H. (Eds). Agro-food Chains and Networks for Development, The Netherlands: Springer, 1era edición.

WILLIAMSON, O. (1994). "Transaction Costs Economics and Organization Theory". En Smelser, N. \& Swedberg, R. (Eds.) The Handbook of Economic Sociology. Princeton NJ: Princeton University Press, 1era edición.

WILLIAMSON, O. (1991). "Comparative Economic Organization: The Analysis of Discrete Structural Alternatives”. En Administrative Science Quarterly, Vol. 36, No.2, pp. 269296.

WILLIAMSON, O. (2003). Transaction Cost Economics and Economic Sociology. Center for the Study of Economy and Society. Working Paper Series No.13. Berkeley: University of California, octubre. Disponible en: http://www.economyandsociety.org/publications/ wp13 Williamson_03.pdf [consultado en febrero de 2005]

WOOD, G. (2003). "Staying Secure, Stayin Poor: The 'Faustian Bargain". En World Development, Vol. 31, No. 3, pp. 455-471.

WOOLCOCK, M.et al. (2000). "Social Capital: Implications for Development, Theory, Research and Policy”. En The World Bank Research Observer, Vol. 15 No.2, pp. 225-249 